\title{
0 futuro da epidemiologia genética de características complexas
}

\author{
Future of genetic epidemiology \\ in complex traits
}

\author{
$M$ ary F. Feitosa 1 \\ $\mathrm{H}$ enrique Krieger 2
}

1 Division of Biostatistics, Campus Box 8.067, Washington University School of M edicine, 660 S. Euclid. Ave. St. Louis, M 0 63110-1093, USA. maryf@wubios.wustl.edu

2 Instituto de Ciências Biomédicas, Universidade de São Paulo, São Paulo, Brasil.

\begin{abstract}
Genetic epidemiology has advanced from its early focus on rare mendelian diseases to the genetic dissection of complex traits. With the advent of the complete genome map of humans and other organisms, morethan ever genetic epidemiology has an important role in ascertaining the relative importance of genetic and environment causative factors of complex traits. The main methodology strategies (familial resemblance, segregation analysis, association and linkage analysis and metaanalysis) in the study of complex traits are outlined and its advantages and shortcomings are discussed. The importance of sampling and the use of appropriate phenotypes and genetic markers are stressed and an example on the study of BM I (Body M ass Index), showing the role of a major genetic factor located at chromosome 7 illustrates some of the above strategies. It is suggested that in the future, although recognizing that multiplex families will still be the mainstay of linkage studies, new and efficient types of sampling (unrelated controls, for instance) utilizing pooled DNA samples will be universally employed. The recognition of genetic heterogeneity between studies and its interpretation will be one of the proeminent features in the forthcoming complex traits studies. Key words Familial resemblance, Segregation analysis, Association and linkage analysis, M eta-analysis, Complex traits
\end{abstract}

Resumo A epidemiologia genética evoluiu de um enfoque em estudos sobre doenças mendelianas raras para a análise genética de características complexas. Com o advento de informações sobre a completa seqüência de genes ao longo do genoma humano e de outros organismos, o interesse da epidemiologia genética em desvendar a natureza dos fatores que influenciam essas características se tornou primordial. São apresentados os princi pais métodos empregados no estudo de doenças com pl exas bem como suas princi pais vantagens e desvantagens. Discute-se a importância na determinação da amostra e o uso de fenótipos e marcadores genéticos apropriados. Como exemplo das estratégias citadas tomamos o estudo de índice de massa corporal (BMI) para ilustrar um fator genético principal localizado no cromossomo 7. Em uma discussão sobre tendências no estudo deligação, embora reconhecendo quefamíliase genealogias continuarão sendo o foco principal das amostras, discute-se alguns novos e eficientes tipos de amostragem (como por exemplo, controles não-relacionados) em que amostras de conjunto de D N A serão universalmente empregadas. 0 reconhecimento da heterogeneidade genética entre estudos e sua interpretação se rá uma das mais importantes características no futuro das análises de características complexas. Palavras-chave Agregação familial, Análise de segr egação, Associação, A nálise de ligação, M eta-análise, Características complexas 
A epidemiologia genética progrediu de sua abordagem inicial em estudos sobre doenças mendelianas raras para a análise de características complexas, ou seja, aquelas que são influenciadas por um grande número de fatores, a maioria dos quais de difícil identificação. D oenças cardiovasculares, pressão arterial, doenças infecciosas e certas neoplasias são exemplos de características complexas. Com a aquisição de informações precisas sobre a seqüência de genes ao longo do genoma humano e de outros organismos, o interesse da epidemiologia genética em desvendar a natureza dos fatores que influenciam essas características se tornou primordial.

Entretanto, essas características têm-se mostrado muito mais desafiadoras e as esperanças de grandes avanços foram frustradas, principalmente devido ao pequeno efeito de cada uma de suas múltiplas causas e pelo fato de que os métodos planejados para detectar genes com efeitos significativos (genes principais) terem se mostrado insuficientes. Contudo, apesar de os efeitos individuais dos genes serem relativamente pequenos, as interações entre esses genes e outros genes e o meio ambiente podem contribuir significativamente para o desven damento dessas características. As dificuldades existentes na detecção dessas interações geralmente redundam na impossibilidade de detectar genes desse tipo.

Para a deteç̧ão dos efeitos dos genes várias condições precisam ser satisfeitas. Em primeiro lugar, obviamente, é necessário o conhecimento adequado da natureza da característica e da sua biologia, história, distribuição etc. Também fundamentais para esse tipo de estudo são o planejamento do estudo apropriado, amostras robustas e o emprego de metodologia adequada.

Seria muito ambicioso pretender, nesse trabalho, fazer uma completa revisão sobre epidemiologia genética. 0 intuito do presente trabaIho é o de dar uma visão geral da área no desvendamento de fatores atuantes em características complexas com ênfase na importância de um delineamento experimental apropriado, no emprego de metodologia correta e nas nuances de interpretação que essas análises podem propiciar. Algumas reflexões sobre a relevância de estudos genético-epidemiológicos em países em desenvolvimento, nesse começo de milênio, quando o grande enigma do mapeamento do genoma humano está concretizado, serão também apresentados.

\section{D elineamento experimental}

A excelência do delineamento do estudo é de vital importância para o mapeamento de genes associados a doenças complexas (Rao, 2001; Gu \& Rao, 2001). U ma abordagem comum para ampliar o poder de um estudo é a utilização de grandes amostras. No entanto, planejamentos simplistas podem conduzir a coleta de amostras enormes que são extremamente difíceis de serem obtidas ou de custo el evadíssimo. Dessa forma, um delineamento criativo é necessário para detectar e ampliar um sinal fraco, porém real.

Estudos multiinstitucionais têm um papel importante na obtenção de grandes amostras coletadas de maneira uniforme pela utilização de protocolos amostrais únicos. N esse sentido, al guns estudos multiinstitucionais têm proporcionado importantes contribuições científicas em diversas áreas da pesquisa biomédica. Exemplos desse tipo de delineamento são o $\mathrm{N}$ ational H eart, Lung, and Blood Institute Family H eart Study (N HLBI-FHS), estudo multiinstitucional que avalia os determinantes genéticos e não-genéticos que atuam em doenças cardiovasculares (Higgins et al., 1996) e o H eritage Family Study, projeto multiinstitucional planejado para estudar o papel de mecanismos genéticos existentes nos fatores de riscos para doenças cardiovasculares e diabetes (Bouchard et al., 1995), ambos nos EUA. Entre nós, um estudo exemplar, que utiliza desse tipo de abordagem, é o Estudo Colaborativo Latino Americano de $M$ alformações Congênitas (ECLAM C) que é um programa clínico e epidemiológico do tipo caso-controle (Prado, 1992).

Os fatores que determinam o conteúdo informativo de um delineamento, que por sua vez regula o poder de decisão de um estudo, podem ser classificados em algumas categorias: 1) fatores associados à fenotipagem e genotipagem; 2) fatores associados à amostragem; 3) procedimentos analíticos; e 4) argumentos associados a custo-ben efício.

Os fenótipos precisam ser claramente definidos. Para evitar que a detecção de um determinado fenótipo seja minimizada, isto é, que a freqüência do fenótipo não seja substancialmente subestimada, a característica em estudo deve ser altamente reproduzível. M edidas múltiplas e/ou o uso de informações suplementares (por exemplo, idade do aparecimento da característica, gravidade da doença, história fa- 
milial etc.) podem contribuir para o refinamento do critério da escolha do fenótipo e podem ser decisivos na melhoria do poder analítico (Rice et al., 2001).

Apesar da constante melhoria tecnológica dos processos automáticos de genotipagem em grande escala, erros na genotipagem ainda existem. Esse fato, acompanhado de possíveis erros na identificação de indivíduos em uma família, pode produzir ruído suficiente para diminuir o poder analítico de um estudo. Portanto, alta qualidade da genotipagem e grande densidade de marcadores ao longo do genoma são fundamentais para o poder de resolução de um estudo. A escolha do tipo de amostragem (grandes genealogias, famílias nucleares, pares de irmãos, caso-controle, isolados populacionais, mistura de populações) e o tamanho da amostra devem ser cuidadosamente escolhidos a fim de conduzir a uma otimização do quociente sinal/ruído. As características complexas possuem provavel mente mecanismos genéticos distintos em populações diferentes (Krieger \& Feitosa 1999) e a escolha da população "apropriada" pode potencializar a qualidade de um estudo (Gu \& Rao, 2001).

Os procedimentos analíticos (segregação, ligação, associação, varredura genômica etc.) devem ser escolhidos por ocasião do planejamento da coleta de dados. Dessa forma, a metodologia torna-se parte do delineamento, possibilitando uma antecipação do poder do estudo. Contudo, se os dados já tiverem sido coletados, um esforço deve ser feito no sentido de escolher o método estatístico mais poderoso visando à otimização dos resultados.

Problemas de custo-benefício devem ser enfrentados no sentido de estabelecer um equilíbrio entre poder e sensibilidade (Gu \& Rao, 2001). U m orçamento fixo e limitações práticas irão provavel mente determinar o tipo de estudo, independentemente das ambições dos pesquisadores. 0 balanço entre custo e eficiência deve ser muito bem estudado antes de se começar um projeto, principalmente em países em desenvolvimento, onde as fontes de financiamento são limitadas e, em geral, parcas.

\section{Procedimentos analíticos}

Os métodos analíticos vêm recebendo contínua aten ção no estudo de características complexas e sua importância para esse tipo de estudo é medida pela inovação metodológica ob- servada nos últimos anos. Aceita-se como fato inquestionável a interdependência absoluta entre técnicas moleculares e métodos estatísticoepidemiológicos, na solução de problemas biológicos relacionados a fenótipos mais ou menos distantes de uma correlação absoluta com um determinado genótipo. Aqui, procuraremos dar uma visão simplificada de alguns métodos da epidemiologia genética empregados na atualidade.

\section{Agregação familial}

A detecção e a avaliação da extensão da agregação familial são os primeiros passos na análise genética de qualquer característica. É sabido que esta agregação significa o compartilhamento, entre indivíduos da mesma família, de genes e de fatores do ambiente. A existência dessa agregação é evidenciada pela maior semeIhança fenotípica entre pares de parentes do que entre dois indivíduos não-aparentados (Elston, 2000, Rice \& Borecki, 2001). A magnitude da agregação familial pode ser medida pe la correlação fenotípica entre pares de indivíduos (ex.: pares de irmãos, pai-filho, cônjuges etc.). Os diversos model os genético-epidemiológicos utilizam essas diversas correlações e a interpretação biológica depende da magnitude e significância dessas correlações.

Vários programas aplicativos encontram-se à disposição do pesquisador para o estudo da agregação familial. Esses programas baseiamse fundamentalmente na aderência de model os a um conjunto de correlações obtido diretamente dos dados, admitindo-se normalidade (no sentido estatístico) multivariada (Hopper \& M attews, 1982). A estimação dos parâmetros do modelo é feita por verossimilhança máxima. Em geral, uma determinada característica é analisada individualmente (análise univariada). Entretanto, alguns estudos podem ser feitos utilizando-se mais de uma característica fenotípica (Coletto et al., 1981). Existem programas altamente eficientes e práticos para trabaIhar essas correlações (ex. SEGPATH ; Province \& Rao, 1995). Em famílias nucleares, o modelo mais simples reconhece a existência de quatro tipos de indivíduos (pais, mães, filhos e filhas), conduzindo a oito tipos de correlações fenotípicas entre indivíduos (pai-mãe, pai-filho, mãe-filho, pai-filho, mãe-filho, filho-filho, fiIho-filha e filha-filha). No caso de simplificar o modelo, admitindo a inexistência de diferenças 
sexuais ou etárias, esse se reduz a três correlações (cônjuges, progenitores-descendentes, irmãos). 0 modelo bivariado completo, que contempla duas características em cada um dos componentes da família nuclear, trabal ha com 34 correlações enquanto que o modelo simplificado, sem diferenças sexuais ou etária, reduzse a dez correlações diferentes. A validade dessas e outras simplificações ou a existência de determinados fatores causais podem ser checadas pelo teste da razão de verossimilhança máxima (RVM) entre o modelo reduzido e um modelo mais geral. As RVM são, assintoticamente, distribuídas como um $\chi^{2}$ com um número de graus de liberdade igual a diferença do número de parâmetros estudados nos dois modelos.

Convém salientar que os estudos de agregação familial vêm de longa data, sendo pioneiros os estudos de $S$. W right eR. A. Fisher na primeira metade do século passado, em conjunto com numerosas contribuições dos meIhoristas, que atestaram pelo caráter clássico desse tipo de estudo e não como sendo devido a modismos tecnológicos.

A correta avaliação da magnitude da contribuição genética à característica fenotípica estudada é fundamental para um delineamento apropriado de estudos que dependem de grandes amostras e técnicas caras de genotipagem.

\section{Análise de segregação}

A análise de segregação é, teoricamente, um método para estudar dados familiares com a finalidade de estabelecer o modo de herança de uma determinada característica, quando o efeito de um gene não pode ser medido diretamente. M endel, no século XIX, foi o pioneiro nesse tipo de análise, que o conduziu à descoberta das leis básicas da hereditariedade. A história da análise de segregação pode, para fins de um melhor entendimento, ser dividida em duas fases: a clássica e a complexa (M orton et al., 1983). Os métodos clássicos de análise de segregação de fenótipos mendelianos estão fundamentados na estimação e teste de razões de segregação (Rao et al., 1974) que são determinados, em grande parte, pelos efeitos de um único gene.

M odelos mais abrangentes de análise de segregação foram desenvolvidos para abordar os problemas gerados por fenótipos complexos (Elston \& Steward, 1971; M orton \& M acClean,
1974; Lalouel et al., 1983; Bonney, 1984; H asstedt, 1982; Blangero \& Konigsberg, 1991). Todos esses diferentes tratamentos metodológicos, apesar de diferirem em al guns pormenores, possuem características comuns que podem ser assim resumidas.

Admite-se que o fenótipo seja influenciado pela contribuição independente e aditiva de um gene principal, um componente poligêni$\mathrm{co/multifatorial} \mathrm{e} \mathrm{um} \mathrm{resíduo} \mathrm{ambiental} \mathrm{não-}$ transmissível. 0 efeito do gene principal resulta da segregação, em um único locus gênico, de dois al elos ( $A$ e e a) e os genótipos são distribuídos nas proporções esperadas pelo princípio de $\mathrm{H}$ ardy-W einberg. Os parâmetros desses modelos são a média $(\mu)$, a variância $(\sigma)$, a freqüência genética ( $q)$, o grau de dominância do gene $(d)$, a herdabilidade $(\mathrm{H})$ e as taxas de transmissão entre duas gerações $(\tau)$.

A análise da segregação tem-se mostrado de grande interesse no estudo de várias características influenciadas por um gene principal ou por um pequeno número de genes (oligogenes) (ex. Blangero et al., 1996; Borecki et al., 1998a; Feitosa et al., 1995, 1996, 1999, 2000a, b, 2002, Olson et al., 2001).

Com as informações de mapas genéticos, modelos de análise de segregação mais reais que incorporem os efeitos de marcadores alojados ou associados (chamados de modelos combinados) serão mais e mais necessários. Certamente, a análise da segregação no futuro próximo utilizará dados sobre marcadores genéticos.

Alguns programas de análise se segregação podem ser obtidos pela internet: POINTER/ COMDS: www.hgmp.mrc.ac.uk/registered/ help/comds; PAP (Pedigree Analysis Package): www.well.ox.ac.uk/docs/indez.html.solar; SOLAR (Sequential Oligogenic Linkage Analysis Routines): http://canag.cit.mih.gov//server/ solar.htm, e SAGE (Statistical Analysis for Genetic Epidemiology): http://darwin.cwru.edu/ pub/sage.html.

\section{Análise de ligação}

Diz-se que há ligação, quando existe uma proximidade mensurável entre genes ao longo do cromossomo. A análise de ligação, em termos de epidemiologia genética, verifica a co-segregação, dentro de uma família, de um genemarcador e um fenótipo para estabelecer se o marcador e a característica estão fisicamente liga- 
dos. A análise da ligação tem sido o método principal para mapear doenças mendelianas e também tem exercido um papel importante nas tentativas de mapear aquelas doenças complexas, que supostamente possuem um mecanismo mendeliano, com efeito, significativo sobre a característica.

Independentemente do tipo de dados à disposição do pesquisador (desde pares de irmãos até extensas geneal ogias), a análise de ligação pode ser realizada por intermédio de técnicas baseadas em modelo (model-based) ou independentes de modelos (model-free). Deve-se frisar que todas as análises estatísticas admitem um modelo probabilístico, no qual parâmetros são estimados e hipóteses sobre parâmetros podem ser testadas.

$N$ as análises baseadas em modelo (ABM), também chamadas de lod-score ou análise paramétrica, admite-se que todos os aspectos do modelo estatístico, exceto a taxa de recombinação $(\theta)$, são conhecidos. M orton (1955) fez uma contribuição fundamental para a genética humana, ao trabal har o conceito de lod-score (lod), ou seja, o logaritmo na base 10 de uma razão de verossimilhança (RV). A RV éa probabilidade de se observar um quadro da distribuição de genótipos em uma família, dada a existência da ligação com um valor q da recombinação versus a mesma probabilidade estimada para segregação independente $(\theta=0,5)$.

Dessa forma, o quociente da verossimiIhança ao valor alternativo $(0 \leq \theta<0,5)$ pelo da mesma ao valor $\theta=0,5$ possui poder de decisão. U m valor maior que três indica que a hipótese alternativa tem uma verossimilhança mil vezes maior que a hipótese nula $\operatorname{com} \theta=$ 0,5 , e é indicativo da existência da ligação entre o marcador e o fenótipo estudado. Valores de lod-scores maiores que 1,5 e menores que três sugerem a existência de ligação, enquanto valores iguais ou menores que - 2 indicam a inexistência de ligação. Elston \& Stewart (1971) produziram um algoritmo para o cálculo de verossimilhança em genealogias complicadas, enquanto Ott (1974) desenvolveu um programa de computador voltado ao usuário para estimar lod-scores nas mais variadas geneal ogias. Os lod-scores têm também sido usados com bastante sucesso, no mapeamento de doenças mendelianas em que são consideradas situações complicadas (penetrância incompleta, dominância, fenocópias, aparecimento tardio, entre outras).

Tendo em vista que a inexistência de um modelo simples de herança para características complexas e, sobretudo, que a mesma pode de pender de co-variáveis (idade de aparecimento, sexo etc.), é muito difícil ou até mesmo impossível obter genealogias multigeracionais informativas sem uma avaliação inicial que possi bilite simplificar a análise dessas genealogias. Dessa forma, o método de pares de irmãos (Penrose, 1935) foi revivido para utilizar os padrões de compartilhamento de al elos no estudo de ligação. A atualização tecnológica do mé todo de pares de irmãos foi ampliada, o que permitiu também a utilização de pares de parentes mais afastados, bem como a análise de determinadas genealogias (Weeks \& Lange, 1988; Curtis \& Sham, 1994; Kruglyak et al., 1996; Almasy \& Blangero, 1998).

$O$ conceito de identidade por ascendência (IBD, I dentity by descent) é de vital importância nos estudos de ligação, pois quantifica a semelhança genética entre pares de indivíduos. U m par de indivíduos aparentados possui um alelo IBD se esse alelo tem origem comum em um ancestral. Dessa forma, um par de irmãos pode possuir zero, um ou dois alelos IBD com as respectivas probabilidades de 1/4, 1/2 e 1/4. Algoritmos para estimar as probabilidades de IBD múltiplos marcadores genéticos constituíram um importante avanço nas pesquisas sobre etiologias complexas ( Lander \& Green, 1987; Sobel \& Lange, 1996; Kruglyak \& Lander, 1998).

Ao contrário do método dependente do modelo, os métodos independentes de modelo não dependem de uma especificação a priori do tipo de herança da característica. Nesses modelos, não é necessário estabelecer-se, a priori, freqüências gênicas e penetrâncias, tendo em vista que funções dessas variáveis e a ta$x a$ de recombinação $(\theta)$ podem ser estimadas simultaneamente.

Para características descontínuas, os métodos independentes do model o contemplam pares de irmãos afetados ou irmandades com pelo menos dois irmãos afetados. Nos estudos com grupos de dois irmãos afetados, o problema de penetrância incompleta é evitado, uma vez que não entram na amostra tanto os indivíduos não-portadores do mecanismo genético como aqueles que possuem a predisposição genética, porém não tendo manifestado a característica.

Se um determinado marcador e uma característica estiveram ligados geneticamente, as proporções de alelos IBD compartilhado $(\pi)$ 
excedem o valor esperado. M uitas análises estatísticas foram desenvolvidas para testar essa hipótese (Blackwelder \& Elston, 1985; Risch, 1990; Kruglyak et al., 1996). Para características contínuas, a semelhança fenotípica pode ser observada diretamente sem a necessidade de escolher irmandades. Sob a hipótese de ligação, irmãos que compartilham uma proporção maior de alelos IBD terão fenótipos mais parecidos, enquanto que sob a hipótese nula (sem ligação) os fenótipos dos pares serão independentes do compartilhamento de alelos, no gene marcador. Várias propostas diferentes foram feitas para estudar esses pares de irmãos e verificar a existência de genes principais influenciando características quantitativas (QTL, Quantitative Trait Locus) e o valor de $\pi$ pode ser estimado através de várias técnicas ( $H$ asemam \& Elston, 1972; Amos, 1994; Almasy \& Blangero, 1998; Province et al., 2001). Excelentes revisões recentes sobre ligação e características complexas podem ser encontradas em O Ison et al. (1999), Elston (2000), e Borecki \& Suarez (2001).

\section{Análise de associação}

A análise de ligação pode ser usada em uma ampla procura por todo o genoma pela existência do locus responsável pela característica, por intermédio de sua localização cromossômica, enquanto que a análise de associação é mais útil para a confirmação de suspeita da participação de um determinado alelo na manifestação de uma certa característica ou de um al elo existente em um locus próximo ao locus responsável pela característica. Em outras palavras, a associação pode existir por duas razões: a) por causa do efeito direto do gene em uma característica em estudo ou, b) quando o marcador estiver em desequilíbrio de ligação com o gene principal responsável pela característica estudada. No primeiro caso, o genótipo pode ser determinado imunologicamente, por métodos el etroforéticos ou diretamente no DNA, sendo que seu efeito pode ser medido na característica estudada. Esse tipo foi chamado por Boerwinkle et al. (1986) de "genótipo medido". No segundo caso, genes anônimos ao invés de marcadores funcionais estão presentes, e dessa forma o teste de associação requer a existência de desequilíbrio de ligação entre a característica e o marcador. Quando ocorre uma mutação causadora de uma doença, a mesma tem lugar em um determinado cromossomo e forma um conjunto haplotípico com os loci adjacentes nesse cromossomo. $\mathrm{N}$ a geração seguinte, a tendência é que esse alelo mutante ocorra no mesmo haplótipo original, excetuando-se os casos de recombinação. Chama-se desequilíbrio de ligação, a ocorrência, na população, de uma freqüência maior de uma determinada combinação entre dois genes, do que a esperada pelo produto de suas freqüên cias individuais. Como visto no exemplo acima, o desequilíbrio da ligação é dependente da taxa de recombinação $(\theta)$ e quanto maior a taxa de recombinação, mais rápida será a aproximação do equilíbrio entre os dois loci.

A pesar de forças evolutivas outras que a mutação (e. g. deriva genética e fluxo gênico) atuarem para alterar o equilíbrio entre loci, é interessante notar que quanto mais antigo for o aparecimento da mutação, mais próxima a população vai estar no equilíbrio.

Existem várias maneiras de testar a existência de associação entre um gene marcador e uma determinada característica. 0 clássico caso-controle, na sua forma mais simples, é uma tabela de contingência $2 \times 2$. A hipótese nula a ser testada é o risco de um indivíduo apresentar a característica independente do marcador. Alguns fatores podem simular uma associação intrínseca e, na verdade, ela ser devida a fatores alheios à associação propriamente dita. Isso pode acontecer, por exemplo, no estudo de uma população estratificada e equivocadamente olhamos a mesma como sendo uniforme. N esse caso a associação pode resultar da estratificação e não da biologia do processo. Dessa forma, se pudermos separar os diversos segmentos (estratos) da população e a associação for espúria, verificaremos que não existirá associação dentro de cada segmento, apenas no total da população. U ma das formas de se evitar uma associação devida à heterogeneidade da população é a utilização de tipos de controles familiais. Falk \& Rubinstein (1987) propuseram um método para avaliar riscos relativos em estudos que usam controles familiais, embora uma década antes, Krieger \& Barbosa (1979) tenham estudado os riscos relativos e as propriedades dependentes das freqüências do marcador em pares de irmãos.

Vários testes estatísticos têm sido sugeridos para esse tipo de estudo, como o risco relativo haplotípico (Falk \& Rubinstein, 1987; Terwilliger \& Ott 1992), controles familiais afetados (Schaid \& Summer, 1994) e o Teste de Desequi- 
líbrio de Transmissão - TDT (Spielman et al., 1993).

O TDT tem recebido atenção particular, pois se baseia tanto em informação de ligação como no desequilíbrio, que são subjacentes à associação. A análise molecular do marcador é importante para esse método, uma vez que visa a uma análise de alta sensibilidade de marcador. Tomam-se amostras de pessoas com uma determinada característica (casos) e estuda-se o marcador neles e em seus progenitores. Para o teste ser informativo, pelo menos um dos progenitores tem que ser heterozigoto para - locus marcador. O TDT usa um teste $\chi^{2}$ de Mc Nermar (1947) para verificar a hipótese nula em que o alelo tido como associado à característica é transmitido em $50 \%$ das vezes pelo progenitor heterozigoto.

0 método TDT foi modificado para lidar com situações mais complicadas, como marcadores multialélicos (Sham \& Curtis, 1995; Bickeboller \& Clérget-D arpoux, 1995; Rice et al., 1995), quando apenas um progenitor é testado (Sun et al., 1999) ou quando ambos os progenitores não podem ser testados, como por exemplo, características de aparecimento tardio (Spielman \& Ewens, 1998; H ovarth \& Laird, 1998; Boehnke \& Langefeld, 1998). N esse caso, a utilização de irmãos não-afetados fornece informação a respeito dos alel os que não é passada aos irmãos afetados.

Recentemente, foram também desenvolvidos métodos que abordam o problema de características quantitativas, utilizando modelos de componentes de variância por intermédio da similaridade familial residual (Boerwinkle et al., 1987; Almasy \& Blangero, 1998; Province et al., 2001). 0 método TDT original foi também ampliado para ser utilizado em características contínuas (Allison, 1997), em situações mais complexas como irmandades com mais de dois indivíduos, alelos múltiplos e em casos que não se referem a hipóteses paramétricas sobre a distribuição da característica (Rabinowitz, 1997). Alternativas que permitem uma abordagem através de regressão em dados genealógicos (George et al., 1999) e vários graus de desequilíbrio de ligação entre o marcador e - locus responsável pela característica (Xiong, 1998) também foram propostas.

Em resumo, como o desequilíbrio de ligação deve persistir na maioria das populações humanas para genes ligados com uma taxa de recombinação menor que $1 \%$, só em situações peculiares é que se tem a sorte de escolher um marcador que preencha esse requisito. Por outro lado, estudos de associação ainda que sabidamente com excesso de resultados fal sos positivos, podem fornecer informações importantes, uma vez que a "história" de recombinação é, de certa forma, utilizada nas análises, tendo em vista que o TDT resolve de maneira satisfatória os problemas causados por falsos positivos devido ao fluxo gênico.

Considerando 0 acima exposto, sugerimos que a procura de genes responsáveis por características complexas seja feita em primeiro plano com um estudo de ligação, com varredura genômica não muito sensível com a finalidade de se identificar as regiões cromossômicas potencialmente candidatas para alojar o gene condicionador das características. Após essa identificação deve se utilizar uma análise mais fina nas regiões promissoras usando densos mapas de polimorfismos de um único nucleotídeo (SNP).

Com essa abordagem, a utilização da informação sobre desequilíbrio de ligação na presença de uma associação positiva pode ser considerada um instrumento para mapeamento fino (Olson et al., 1999, Borecki \& Suarez, 2001 e Baron, 2001).

\section{Meta-análise}

M eta-análise pode ser entendida como sendo a utilização de toda a informação existente sobre a possível identificação de um gene principal oriundo de vários estudos. Sabidamente, características complexas são identificadas pela existência de interações entre genes e ambiente, portanto o efeito de um gene em particular deve ser relativamente pequeno. Assim, a metaanálise se propõe a juntar sinais relativamente fracos de estudos particulares, em um conjunto mais robusto de evidências sobre efeitos genéticos, bem como permitindo um arcabouço quantitativo para modelar a variabilidade entre estudos. A aplicação desse tipo de análise, utilizando várias abordagens estatísticas (Olkin, 1995), tem sido relativamente freqüente nos últimos anos (Li \& Rao, 1996, Rice, 1998).

Diferentes estudos de características complexas variam entre si por numerosas razões: definições fenotípicas diferentes; averiguação e escolha tanto dos marcadores genéticos como da metodologia estatística. Dessa forma, diferentes conclusões a respeito de ligação podem ser devidas tanto ao delineamento do estudo, 
como pela presença de diferentes fatores gené ticos.

Contudo, se um esforço for despendido em rever todos os estudos e os artefatos forem cautelosamente identificados, a meta-análise dos estudos disponíveis pode resultar em um conjunto poderoso para a detecção de genes com pequenos efeitos individuais.

É de especial interesse o estudo de metaanálise de resultado de ligação levada adiante por Gu et al. (1998), apresentando métodos para agregar resultados em uma análise de dados de pares de irmãos, usando a proporção de alelos que compartilham IBD no locus marcador e do efeito comum do possível locus. Efeitos aleatórios foram incluídos no modelo para caracterizar a variabilidade entre amostras, enquanto que outras estimativas (por quadrados mínimos, no caso) foram usadas para avaliar os prováveis efeitos do gene principal. Vários resultados suplementares puderam ser obtidos incorporando variáveis específicas em análises com co-variáveis que pudessem explicar a variabilidade entre estudos ( $\mathrm{Gu}$ et al., 1999, 2001).

U ma indicação de importância desse tipo de abordagem pode ser avaliada pelo interesse de firmas independentes em se associar a esse esforço. Existe uma firma dedicada à varredura genômica (Genoma Search M eta-A nalysis/ GSM A) que permite a agregação de novos dados a estruturas já existentes para integrar os novos dados a bancos de dados já atuantes (W ise et al., 1999). Pormenores sobre meta-análise podem ser vistos em um recente trabalho de Gu et al., (2001).

\section{Exemplos à guisa de ilustração}

Alguns estudos evidenciaram a existência de um possível locus influenciando diversos fenótipos complexos (Comuzzie et al., 2001; Baron, 2001) e nessa revisão, tomamos como exemplo o fenótipo Índice de M assa Corporal (BMI Body M ass Index, que é o clássico índice gerado pelo quociente do peso corporal pelo quadrado da altura). O BM I é a influência de vários fatores causais, uma vez que representa a quantidade de massa corporal, a composição corporal e proporções, sendo certamente efeito de vários processos metabólicos, de efeitos hormonais, de comportamento e de interações entre esses fatores etiológicos de amplo espectro.
A maioria dos estudos estimou a herdabilidade do BMI como estando entre 40-55\% (Bouchard et al., 1998, Borecki et al., 1998b e Rice et al., 1999). Contudo, convém salientar que herdabilidades acima de $80 \%$ foram descritas em estudos de gêmeos. A pesar do BM I ser uma característica complexa, os estudos de segregação têm sugerido evidência de um ou dois genes controlando a sua variabilidade em diferentes populações/amostras (Province et al., 1990; H asstedt et al., 1997, Borecki et al., 1998b).

U ma varredura genômica usan do componentes de variância baseados em uma análise de ligação multilócica para BMI indicou fortemente a existência de ligação no cromossomo $7 q 32.3(\operatorname{lod}=4,9, p<10-5)$ no estudo familial N HLBI - Family Heart Study (Feitosa et al., 2002b). Prévios estudos já haviam sugerido evidência de ligação na região cromossômica do locus LEP com al gumas características de medidas de obesidade (D uggirala et al., 1996; Clément et al., 1996; Roth et al., 1997; Lapsys et al., 1997; bray et al., 1999). Deve-se também salientar que uma meta-análise baseada em cinco estudos levada a cabo por Allison e $\mathrm{HeO}$ (1998) demonstrou forte evidência de ligação e associação do $B M I$ à região LEP $(p=1.5 \times 10$ $5)$. N ão se deve perder de vista, porém, que alguns estudos indicaram associações do BM I com loci pertencentes a outros cromossomos (Pérusse et al., 2001).

\section{0 futuro da epidemiologia genética}

É claro que o delineamento de estudos ainda será o fator primordial dos estudos futuros e, é claro, também que dados familiais continuarão sendo o melhor arsenal para estudos nessa área.

Contudo, alguma substituição de amostras com controles familiais poderá ser necessária para cobrir lacunas na literatura. Estudos de caso-controle de indivíduos não-relacionados, especialmente para análises de dados com marcadores de DNA, poderão fornecer robustas evidências para estudos de ligação.

A heterogeneidade genética pode ser uma das facetas proeminentes dos estudos sobre características complexas. A amostragem de famílias de procedências étnicas diferentes serão de grande importância para desvendar mecanismos causais e também na identificação de fatores modificadores tanto genéticos como do 


\section{Referências bibliográficas}

Allison DB \& Heo M 1998. M eta-analysis of linkage data under worst-case conditions: a demonstration using the human OB region. Genetics 148:859-865.

Allison DB 1997. Transmission-disequilibrium tests for quantitative traits. Am. J. H um. Genet. 60(3):676-90.

Almasy L \& Blangero J 1998. M ultipoint quantitativetrait linkage analysis in general pedigrees. Am. J. Hum. Genet. 62(5):1.198-1.211.

Amos Cl 1994. Robust variance-components approach for assessing genetic linkage in pedigrees. Am. J. Hum. Genet. 54(3):535-543.

Baron M 2001. The search for complex disease genes: fault by linkage or fault by association? M ol. Psychiatry 6(2):143-149.

Bickeboller H \& Clérget-Darpoux F 1995. Statistical properties of the allelic and genotypic transmission/disequilibrium test for multiallelic markers. Genet. Epidemiol. 12(6):865-870.

Blackwelder WC \& Elston RC 1985. A comparison of sibpair linkage tests for disease susceptibility loci. Genet. Epidemiol. 2(1):85-97.

Blangero J \& Konigsberg LW 1991. M ultivariate segregation analysis using the mixed model. Genet. Epidemiol. 8(5):299-316.

Blangero J, Williams-Blangero S, M ahaney MC, Comuzzie AG, Hixson JE, Samollow PB, Sharp RM, Stern MP \& M acCluer JW 1996. Effects of a major gene for apolipoprotein A-I concentration are thyroid hormone dependent in M exican Americans. Arterioscler. Thromb. Vasc. Biol. 16(9):1.177-1.183.

Boehnke M \& Langefeld CD 1998. Genetic association mapping based on discordant sib pairs: the discordant-alleles test. Am. J. H um. Genet. 62 (4):950-961.

Boerwinkle E \& Chakraborty R, Sing CF 1986. The use of measured genotype information in the analysis of quantitative phenotypes in man. I. M odels and analytical methods. Ann. Hum. Genet. 50(Pt 2):181-194.

Boerwinkle E, Visvikis S, W elsh D, Steinmetz J, H anash SM , Sing CF 1987. The use of measured genotype information in the analysis of quantitative phenotypes in man. II. The role of the apolipoprotein E polymorphism in determining levels, variability, and covariability of cholesterol, betalipoprotein, and triglycerides in a sample of unrelated individuals. Am. J. M ed. Genet. 27(3):567-582.

Bonney GE 1984. On the statistical determination of major gene mechanisms in continuous human traits: regressive models. Am. J. M ed. Genet. 18(4):731-749.

Borecki IB, Blangero J, Rice T, Perusse L, Bouchard C \& Rao DC 1998a. Evidence for at least two major loci influencing human fatness. Am. J. Hum. Genet. 63(3): 831-838.

Borecki IB, Higgins M, Schreiner PJ, Arnett DK, M ayerDavis E, H unt SC \& Province M A 1998b. Evidence for multiple determinants of the body mass index: the N ational H eart, Lung, and Blood Institute Family H eart Study. O bes. Res. 6:107-114

Borecki IB \& Suarez BK 2001. Linkage and association: basic concepts. Adv. Genet. 42:45-66.

Bouchard C, Leon AS, Rao DC, Skinner JS, Wilmore JH \& Gagnon J 1995. The Heritage family study. Aims, design, and measurement protocol. M ed. Sci. Sports Exerc. 27:721-729.
Bouchard C, Pérusse L, Rice T \& Rao DC 1998. The genetics of human obesity. In $\mathrm{H}$ andbook of $\mathrm{O}$ besity, GA. Bray, C Bouchard, and W PT James eds. N ova York: $M$ arcel Dekker, Inc, pp. 157-190.

Bray MS, Boerwinkle E \& Hanis CL 1999. Linkage analysis of candidate obesity genes among the M exicanAmerican population of Starr County, Texas. Genet. Epidemiol. 16:397-411.

Clément K, Garner C, Hager J, Philippi A, LeDuc C Carey $A, H$ arris TJ, Jury $C$, Cardon LR, Basdevant $A$, Demenais F, Guy-Grand B, North M \& Froguel $P$ 1996. Indication for linkage of the human OB gene region with extreme obesity. Diabetes 45:687-690.

Coletto GM DD, Krieger H \& M agalhães JR 1981. Estimates of the genetical and environmental determinants of serum lipid and lipoprotein concentrations in Brazilian twins. Hum. Hered. 31: 232-237.

Comuzzie AG, Williams JT, M artin LJ \& Blangero J 2001. Searching for genes underlying normal variation in human adiposity. J. M ol. M ed. 79(1):57-70.

Curtis D \& Sham PC 1994. Using risk calculation to implement an extended relative pair analysis. Ann. Hum. Genet. 58( Pt 2):151-162.

Duggirala R, Stern M P, M itchell BD, Reinhart LJ, Shipman $P A$, U resandi OC, Chung WK, Leibel RL, Hales CN, O 'Connell P \& Blangero J 1996. Quantitative variation in obesity-related traits and insulin precursors linked to the $\mathrm{OB}$ gene region on human chromosome 7. Am. J. H um. Genet. 59:694-703.

Elston RC \& Stewart J 1971. A general model for the genetic analysis of pedigree data. H um. H ered. 21(6): 523-542.

Elston RC 2000. Introduction and overview. Statistical methods in genetic epidemiology. Stat. M ethods $M$ ed. Res. 9(6):527-541.

Falk CT \& Rubinstein P 1987. H aplotype relative risks: an easy reliable way to construct a proper control sample for risk calculations. Ann. H um. Genet. 51 (Pt 3):227-233

Feitosa M F, Borecki I, Krieger H, Beiguelman B \& Rao DC 1995. The genetic epidemiology of leprosy in a Brazilian population. Am. J. Hum. Genet. 56: 1.1791.185.

Feitosa M F, Krieger H, Borecki I, Beiguelman B \& Rao DC 1996. The genetic epidemiology of $M$ itsuda reaction in leprosy. H um. H ered. 46:32-35.

Feitosa M F, Rice T, Nirmala-Reddy A, Reddy PC \& Rao DC 1999. Segregation analysis of regional fat distribution in families from Andhra Pradesh, India. Int. J. O bes Relat. M etab. Disord. 23(8):874-880.

Feitosa M F, Rice T, N irmala A \& Rao DC 2000a. M ajor gene effect on body mass index: the role of energy intake and energy expenditure. Hum. Biol. 72(5):781-799.

Feitosa M F, Borecki I, H unt SC, Arnett DK, Rao DC \& Province M 2000b. Inheritance of the waist-to-hip ratio in the $\mathrm{N}$ ational $\mathrm{H}$ eart, Lung, and Blood Institute Family H eart Study. O bes. Res. 8(4):294-301.

Feitosa MF, Rice T, Rosmond R, Borecki IB, An P, Gagnon J, Leon AS, Skinner JS, Wilmore JH, Bouchard C \& Rao DC 2002a. A genetic study of cortisol measured before and after endurance training: The Heritage Family Study. M etabolism(no prelo). 
Feitosa M F, Borecki I, Rich SS, Arnett DK, Rao DC Phyliss Sholinsky $P$, Myers RH, Leppert $M \&$ Province M 2002b. Quantitative Trait Loci Influencing Body M ass Index Resides on Chromosomes 7 and 13: The N ational Heart, Lung, and Blood Institute Family Heart Study (FHS). Am. J. H um. Genet. 7:72-82.

George V, Tiwari HK, Zhu X \& Elston RC 1999. A test of transmission/disequilibrium for quantitative traits in pedigree data, by multiple regression. Am. J. Hum. Genet. 65(1):236-245.

Gu C, Province M, Todorov A \& Rao DC 1998. M etaanalysis methodology for combining non-parametric sibpair linkage results: genetic homogeneity and identical markers. Genet. Epidemiol. 15(6):609-626.

Gu C, Province M \& Rao DC 1999. A meta-analysis approach for pooling sibpair linkage studies with study-specific covariates: mixed effects models. Genet. Epidemiol. 17(suppl. 1):599-604.

Gu C, Province M \& Rao DC 2001. M eta-analysis for model-free methods. Adv. Genet. 42:255-272.

Gu C \& Rao DC 2001. Optimum study designs. Adv Genet. 42:439-457.

Haseman JK \& Elston RC 1972. The investigation of linkage between a quantitative trait and a marker locus. Behav. Genet. 2(1):3-19.

Hasstedt SJ 1982. A mixed-model likelihood approximation on large pedigrees. Comput. Biomed. Res. 15(3) 295-307.

H asstedt SJ, H offman M , Leppert M F \& Elbein SC 1997. Recessive inheritance of obesity in familial non-insulin-dependent diabetes mellitus, and lack of linkage to nine candidate genes. Am. J. H um. Genet. 61 668-677.

Higgins M , Province M , H eiss G, Eckfeldt J, Ellison RC, Folsom AR, Rao DC, Sprafka JM \& Williams R 1996. NHLBI family heart study: objectives and design. Am. J. Epidemiol. 143(12):1.219-1.228.

Hopper JL \& M athews JD 1982. Extensions to multivariate normal models for pedigree analysis. Ann. H um. Genet. 46 (4):373-383.

Horvath S\& Laird N M 1998. A discordant-sibship test for disequilibrium and linkage: no need for parental data. Am. J. H um. Genet. 63(6):1.886-1.897.

Krieger H \& Barbosa CAA 1979. Smallpox and the ABO system association: a critical review. Rev. Brasil. Biol. 39(1):195-199.

K rieger H \& Feitosa M F 1999. Genetic epidemiology of infectious disease. Ciência e Cultura: J ournal of the Brazilian Association for the Advancement of Science 51:191-198.

Kruglyak L \& Lander ES 1998. Faster multipoint linkage analysis using Fourier transforms. J. Comput. Biol. 5(1):1-7.

Kruglyak L, Daly MJ, Reeve-Daly M P\& Lander ES 1996. Parametric and nonparametric linkage analysis: a unified multipoint approach. Am. J. Hum. Genet. 58(6):1.347-1.363.

Lalouel JM, Rao DC, M orton NE \& Elston RC 1983. A unified model for complex segregation analysis. Am. J. Hum. Genet. 35(5):816-26.

Lander ES \& Green P 1987. Construction of multilocus genetic linkage maps in humans. Proc. Natl. Acad. Sci. U S A. 84(8):2.363-2.367.

Lapsys N M , Furler SM, M oore KR, N guyen TV, Herzog
H, H oward G, Samaras K, Carey D G, M orrison NA, Eisman JA \& Chisholm DJ 1997. Relationship of a novel polymorphic marker near the human obese (OB) gene to fat mass in healthy women. 0 bes. Res. 5:430-433.

Li Z \& Rao DC 1996. Random effects model for metaanalysis of multiple quantitative sibpair linkage studies. Genet. Epidemiol. 13(4):377-383.

M cNemar Q 1947. N ote on the sampling error of the difference between correlated proportions or percentages. Psychometrika 12:153-157.

M orton NE \& M acLean CJ 1974. Analysis of family resemblance. 3. Complex segregation of quantitative traits. Am. J. Hum. Genet. 26(4):489-503.

M orton NE 1955. Sequential tests for the detection of linkage. Am. J. H um. Genet. 7:277-318.

M orton NE, Rao DC \& Lalouel JM 1983. M ethods in ge netic epidemiology. (Contributions to genetic epidemiology and biostatistics; v. 4). Ed. Basel, N ova York: Karger. 261 pp.

Olkin I 1995. M eta-analysis: reconciling the results of independent studies. Stat. M ed. 14(5-7):457-472.

Olson JM, Witte JS, Elston RC 1999. Genetic mapping of complex traits. Stat. M ed. 18(21):2.961-2.981.

Olson JE, Atwood LD, Grabrick DM, Vachon CM, Sellers TA 2001. Evidence for a major gene influence on abdominal fat distribution: the M innesota Breast Cancer Family Study. Genet. Epidemiol. 20(4):458478.

Ott J 1974. Estimation of the recombination fraction in human pedigrees: efficient computation of the likelihood for human linkage studies. Am. J. Hum. Genet. 26(5):588-597.

Penrose LS 1935. The detection of autosomal linkage in data which consist of pairs of brothers and sisters of unspecified parentage. Ann. Eugen. (London) 6:133138.

Pérusse L, Chagnon YC, W eisnagel SJ, Rankinen T, Snyder E, SandsJ \& Bouchard C 2001. The human obesity gene map: the 2000 update. Obes. Res. 9(2):135169.

Prado RAR 1992. Curriculum vitae del estudio colaborativo latinoamericano de malformaciones congénitas (ECLAM C), 1967-1992. Universidade Federal do Rio de Janeiro, Rio de Janeiro. 188 pp.

Province M A, Arnqvist P, Keller J, Higgins M \& Rao DC 1990. Strong evidence for a major gene for obesity in the large unselected total community healthy study of Tecumseh. Am. J. H um. Genet. 47(suppl.):A143.

Province M A \& Rao DC 1995. A general purpose model and a computer program for combined segregation and path analysis (SEGPATH): automatically creating computer programs from symbolic language model specifications. Genet. Epidemiol. 12:203-219.

Province M A, Rice T, Borecki IB, Gu C \& Rao DC 2001. A multivariate and multilocus variance components approach using structural relationships to assess quantitaive trait linkage via SEGPATH. Genet. Epidemiol. (no prelo).

Rabinowitz D 1997. A transmission disequilibrium test for quantitative trait loci. H um. H ered. 47(6):342350.

Rao DC, M orton NE \& Yee S 1974. Analysis of family resemblance. II. A linear model for familial correlation. Am. J. H um. Genet. 26(3):331-59.

Rao DC 2001. Genetic dissection of complex traits: an 
overview. Adv. Genet. 42:13-34.

Rice JP, Neuman RJ, Hoshaw SL, Daw EW \& Gu C 1995. TDT with covariates and genomic screens with mod scores: their behavior on simulated data. Genet. Epidemiol. 12(6):659-664.

Rice JP 1998. The role of meta-analysis in linkage studies of complex traits. Am. J. M ed. Genet. 74:112-114.

Rice JP, Saccone NL \& Rasmussen E 2001. Definition of the phenotype. Adv. Genet. 42:69-76.

Rice T, Perusse L, Bouchard C \& Rao DC 1999. Familial aggregation of body mass index and subcutaneous fat measures in the longitudinal Quebec family study. Genet. Epidemiol. 16(3):316-34.

Rice T \& Borecki IB 2001. Familial resemblance and heritability. Adv. Genet. 42:35-44.

Risch N 1990. Linkage strategies for genetically complex traits. I. Multilocus models. Am. J. Hum. Genet. 46(2): :222-228.

Roth H, Hinney A, Ziegler A, Barth N, Gerber G, Stein K, Bromel T, M ayer H, Siegfried W, Schafer H, Remschmidt H, Grzeschik KH \& H ebebrand J 1997. Further support for linkage of extreme obesity to the obese gene in a study group of obese children and adolescents. Exp. Clin. Endocrinol. Diabetes 105:341344.

Schaid DJ \& Sommer SS 1994. Comparison of statistics for candidate-gene association studies using cases and parents. Am. J. Hum. Genet. 55(2):402-409.

Sham PC \& Curtis D 1995. An extended transmission/ disequilibrium test (TDT) for multi-allele marker loci. Ann. Hum. Genet. 59 (Pt 3):323-336.

Sobel E \& Lange K 1996. Descent graphs in pedigree analysis: applications to haplotyping, location scores, and marker-sharing statistics. Am. J. H um. Genet. 58(6):1.323-1.337.

Spielman RS, M cGinnis RE \& Ewens WJ 1993. Transmission test for linkage disequilibrium: the insulin gene region and insulin-dependent diabetes mellitus (IDDM ). Am. J. H um. Genet. 52(3):506-516.

Spielman RS \& Ewens WJ 1998. A sibship test for linkage in the presence of association: the sib transmission/ disequilibrium test. Am. J. H um. Genet. 62(2):450458.

Sun F, Flanders WD, Yang Q \& Khoury MJ 1999. Transmission disequilibrium test (TDT) when only one parent is available: the 1-TDT. Am. J. Epidemiol. 150(1):97-104.

Terwilliger JD \& Ott J 1992. A haplotype-based 'haplotype relative risk' approach to detecting allelic associations. Hum. Hered. 42(6):337-346.

Weeks DE \& Lange K 1988. The affected-pedigree-member method of linkage analysis. Am. J. H um. Genet. 42(2):315-326.

Wise LH , Lanchbury JS \& Lewis CM 1999. M eta-analysis of genome searches. Ann. H um. Genet. 63(Pt 3):263272.

Xiong M M , Krushkal J \& Boerwinkle E 1998. TDT statistics for mapping quantitative trait loci. Ann. Hum. Genet. 62( Pt 5):431-452. 